\title{
Commentary: Another technique for biventricular repair of double-outlet right ventricle with noncommitted ventricular septal defect
}

\author{
Francois Lacour-Gayet, MD
}

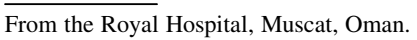

Disclosures: Author has nothing to disclose with regard to commercial support.

Received for publication July 31, 2019; accepted for publication July 31, 2019; available ahead of print Oct 4, 2019.

Address for reprints: Francois Lacour-Gayet, MD, 15 Bis Rue Rousselet, 75007 Paris, France (E-mail: flacourgayet@mac.com).

J Thorac Cardiovasc Surg 2020;159:2406

$0022-5223 / \$ 36.00$

Copyright (C) 2019 Published by Elsevier Inc. on behalf of The American Association for Thoracic Surgery

https://doi.org/10.1016/j.jtcvs.2019.07.123

The article in this issue of the Journal by Lu and colleagues ${ }^{1}$ from Changsha, Hunan Province, China, reports a new technique for biventricular repair of double-outlet right ventricle with noncommitted VSD (DORV-ncVSD) by using an intraventricular conduit to connect the ventricular septal defect (VSD) to the aorta. This technique was previously mentioned, but no experience has been published until this report. The indication for this technique is limited to children older than 2 years (2-23 years). In a series of 31 patients, 12 children aged 2 to 5 years received a $16-\mathrm{mm}$ conduit and 19 older than 5 years received a $19-\mathrm{mm}$ conduit. The VSD was enlarged in 18 cases $(58 \%)$. There were only 1 operative death $(3.2 \%)$ and 1 late death. No reoperations were required during a median follow-up of 7.7 years.

This series was achieved with very limited mortality and morbidity. There are 2 main limitations, however, to this intraventricular conduit technique. The first is the risk of impairing the tricuspid valve when suturing the proximal end of the conduit around the VSD in close contact with the conal papillary muscle. The second is the risk of late left ventricular outflow tract obstruction with conduits sized $16 \mathrm{~mm}$, which will likely require reoperation in adulthood. A 19-mm conduit is probably the smallest acceptable size to avoid late subaortic obstruction. The question raised is whether this quite safe technique should be generalized to all DORV-ncVSD. The answer is probably no. The technique would be better indicated in "true" remote VSD with restrictive distance between the tricuspid and pulmonary valves and in patients with pulmonary stenosis or atresia. The definition of DORV-ncVSD remains controversial. Defining remote VSD as a VSD located below the posterior limb of the trabecular septomarginalis seems more objective than defining it in terms of distance from VSD

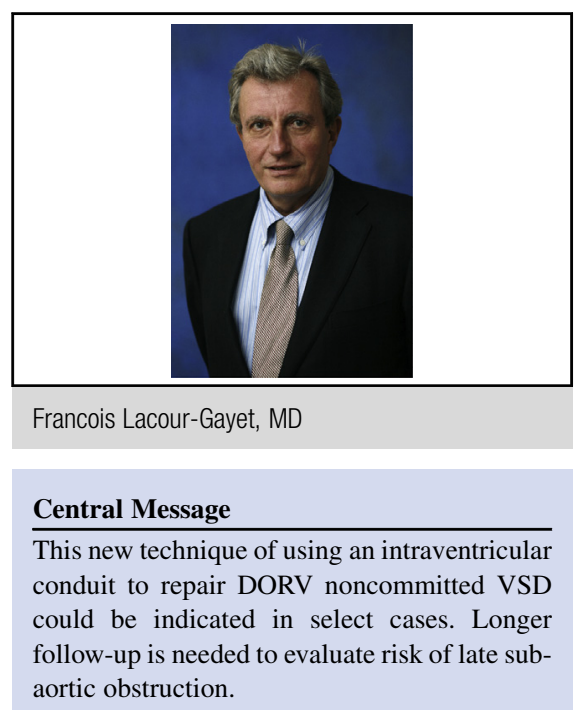

See Article page 2397.

to the aorta longer than an aortic annulus. ${ }^{2}$ In addition, other techniques have been successfully used. Double root translocation has shown good results. ${ }^{3}$ The technique of tunelizing the VSD to the pulmonary infundibulum followed by arterial switch is a good option in patients without pulmonary obstruction and can be used in patients younger than 2 years. ${ }^{2}$ Lu and colleagues ${ }^{1}$ are to be congratulated for their excellent results on an innovative technique. They are to be commended for their commitment to support biventricular repair in the surgery of DORV-ncVSD.

\section{References}

1. Lu T, Li J, Hu J, Huang C, Tan L, Wu Q, et al. Biventricular repair of double-outlet right ventricle with noncommitted ventricular septal defect using intraventricular conduit. J Thorac Cardiovasc Surg. 2020;159:2397-403.

2. Lacour-Gayet F. Bi-ventricular repair of double outlet right ventricle. In: LacourGayet F, Bove EL, Hraška V, Morell VO, Spray TL, eds. Surgery of Conotruncal Anomalies. London: Springer; 2016:391-414.

3. Li S, Ma K, Hu S, Hua Z, Yan J, Pang K, et al. Biventricular repair for double outlet right ventricle with non-committed ventricular septal defect. Eur J Cardiothorac Surg. 2015;48:580-7; discussion 587. 